\title{
A INTERFACE ENTRE A FAMÍLIA E O DIREITO AO ENSINO BILÍNGUE PARA SUJEITOS SURDOS: ROMPENDO OPOSIÇÕES BINÁRIAS
}

\author{
THE INTERFACE BETWEEN THE FAMILY AND THE RIGHT TO BILINGUAL \\ EDUCATION FOR DEAF PERSONS: BREAKING BINARY OPPOSITIONS
}
INTERFACE ENTRE LA FAMILIA Y EL DERECHO A LA ENSEÑANZA BILÍNGUE PARA SUJETOS SURDOS: ROMPENDO OPOSICIONES BINARIAS

Sílvia Andreis Witkoski ${ }^{1}$

\begin{abstract}
Resumo
O presente artigo busca problematizar a interface entre a família e o acesso real ao ensino bilíngue, desvelando as intrínsecas relações existentes entre as possibilidades dos sujeitos surdos de usufruir deste direito, previsto no Decreto no 5.626/2005. Tal direito, que pressupõe o uso da Língua Brasileira de Sinais como primeira língua, e da Língua Portuguesa, como segunda, antecede a entrada daqueles na escola, devendo ser promovido no ambiente familiar, desde a descoberta da surdez. A maioria das famílias, no entanto, nega o mesmo, na medida em que opta pelo caminho da normalização de seus filhos. Para romper este ciclo de negação do direito ao bilinguismo, considera-se fulcral problematizar a essência que envolve as questões, umbilicalmente articuladas, entre identidade e diferença, revisitando os pilares que constroem os binarismos pelos quais o ouvinte é perspectivado como "normal" e o sujeito surdo, como "anormal", rumo à desnaturalização da "norma".
\end{abstract}

Palavras-chaves: Surdos. Bilinguismo. Família. Língua de Sinais. Direito.

\begin{abstract}
This article seeks to discuss the interaction between the family and real access to bilingual education, revealing the intrinsic relationship between the possibilities of deaf people taking advantage of the right provided for in Decree No. 5,626 / 2005. This right presupposes the use of Brazilian Sign Language (Libras) as the child's first language, and Portuguese, as the child's second language. That order should be implemented before starting school and promoted in the family environment, once the child's deafness is discovered. Most families, however, deny such an environment, instead choosing a path of normalization for their children. To break this cycle of denial of the right to bilingualism, it is considered crucial to question the essence surrounding the issues, inextricably articulated, between identity and difference, revisiting the pillars that build the idea in which the hearing child is viewed as "normal" and the deaf child as "abnormal", toward the denaturalization of the "norm."
\end{abstract}

Keywords: Deafness. Bilingualism. Family. Sign Language. Rights.

\section{RESUMEN}

El presente artículo busca problematizar una interfaz entre la familia y el acceso reales a la enseñanza bilingüe, desvelando como intrínsecas relaciones existentes entre como posibilidades de los sujetos sordos de usufructuar de este derecho, previsto en el Decreto no 5.626 / 2005. Tal Derecho, que presupone el USO de la USO La primera lengua, y de la lengua portuguesa, segunda como, anteceder la entrada de aquellos en la escuela, promovido debiendo ser ningún ambiente familiar, desde el

\footnotetext{
${ }^{1}$ Pós-doutorado em Educação - Universidade Federal do Paraná (UFPR) - Curitiba, PR - Brasil. Professora Adjunta Universidade Tecnológica Federal do Paraná (UTFPR) - Curitiba, PR - Brasil. E-mail: silviaandreis@hotmail.com
}

(C) ETD-Educação Temática Digital Campinas, SP $\quad$ v.19 n.3 $\quad$ p. $882-900 \quad$ jul./set. 2017 
descubrimiento de la sordera. La mayoría de las familias, sin embargo, niega el MISMO, en la medida en que opta por el camino de la normalización de sus hijos. Para romper este ciclo de negación hacer Derecho al bilingüismo, se considerará crucial resolver la Esencia Que desarrolle de como Cuestiones, umbilicalmente Articuladas, entre Identidad y Diferencia, revisitando los pilares que construyen los binarismos por los que el oyente y contemplado como "normal" y el " Sujeto sordo, como "anormal", hacia la desnaturalización de la "norma".

PALABRAS CLAVE: Sordos. Bilingüismo. Familia. Lengua de signos. Derecho.

\section{INTRODUÇÃO}

A Língua Brasileira de Sinais, Libras, obteve seu reconhecimento em 24 de abril de 2002, por meio da Lei no 10.436 como meio legal de comunicação e expressão de comunidades de pessoas surdas do Brasil. Em 2005, a Lei de Libras, como ficou conhecida, foi regulamentada pelo Decreto $\mathrm{n}-5.626$, que estabeleceu inúmeras prerrogativas em relação ao direito dos surdos à educação bilíngue.

Observa-se que, segundo a definição expressa no próprio Decreto, educação bilíngue pressupõe que a Língua Brasileira de Sinais (Libras) seja considerada a primeira língua do aluno surdo, e a Língua Portuguesa, a segunda. E para promover este ensino está prevista, na referida legislação, a possibilidade de oferta desta em escolas e/ou classes bilíngues de surdos bem como em escolas comuns da rede regular, em sistema de inclusão. Neste caso, com docentes sabedores da singularidade linguística deste alunado, bem como com a presença do Intérprete de Língua de Sinais (ILS).

Importante ressaltar, no entanto, que a decisão sobre a criança ter acesso ao direito de receber uma educação bilíngue, assim como que escola frequentar, se regular ou de surdos, por exemplo, é delegada aos pais. O que é um direito legítimo, se considerarmos que 90 a 95\% das crianças surdas nascem em famílias ouvintes, que em sua maioria, desconhecem as implicações sociais, linguísticas, educacionais e emocionais do ser surdo, leva a pensar que tal atribuição deveria, no mínimo, ser problematizada.

A questão não está em discutir a responsabilização, que deve ser um direito inviolável. O cerne se encontra no fato de que é atribuída, a estes pais, uma decisão a ser tomada, sem o apoio de sólidas informações que os habilite a escolher o melhor caminho educacional para seus filhos. É um contrassenso que a legislação favorece, na medida em que, apenas no capítulo VII do Decreto supracitado, se refere à garantia do direito à saúde das pessoas surdas ou com deficiência auditiva. E, de forma generalista, prevê que o Sistema Único de Saúde, assim como as empresas que detêm concessão ou permissão de serviços públicos de assistência à saúde, devem garantir "orientações 
à família sobre as implicações da surdez e sobre a importância de as crianças com perda auditiva terem, desde seu nascimento, acesso à Libras e à Língua Portuguesa." (BRASIL, 2005).

A lacuna presente na legislação brasileira, ao não definir quem e como, a priori, deve se responsabilizar pelas orientações a serem fornecidas à família, tem se traduzido em um vácuo de desinformação diante do qual a maioria dos pais submerge em desespero. A situação é agravada quando, ao diagnosticar, a maior parte dos médicos, adeptos da abordagem da medicalização da surdez ${ }^{2}$, confere a esta um grau de dramaticidade. Conforme Souza (2007), neste momento seria mais adequado que eles, além de informar sobre os recursos tecnológicos disponíveis, como as diferentes próteses, por exemplo, explicando sua real funcionalidade, também orientassem sobre a importância da Língua de Sinais para as crianças, destacando os ganhos linguísticos e afetivos que esta implica, e evidenciando o fato de que a Libras não interfere negativamente na aquisição da oralidade.

Com isso, a maioria destes profissionais deixa de prover informações claras, precisas e imparciais. Acabam por assinalar, como referido, uma perspectiva fatalista em relação ao futuro destes filhos, por serem surdos. Vale ressaltar que este "olhar" não está presente apenas na área médica, mas nas representações sociais historicamente enraizadas, não se restringindo apenas a crianças diagnosticadas com surdez. Predomina em relação a indivíduos que apresentam alguma deficiência, de modo que passam a ser tidos como incapacitados, sendo baixa ou nula a eficácia atribuída a estes, vistos, então, como "um fardo". (HEATHERTON et al., 2000, p. 39). Estas são as características ainda aceitas no senso comum, tão naturalizadas que transparecem, inclusive, no modo pejorativo como as pessoas se referem às deficiências, no dia a dia:

\footnotetext{
"Você é cego?"; "Você é surdo?"; "Você é retardado?"; "Você é louco?" Ou as expressões: "uma pergunta imbecil", "uma resposta capenga", "um ponto cego", [...]. Ou insultos: "idiota", "cretino", "lunático", "imbecil". O que há em comum entre todos os exemplos acima é que a língua relacionada às deficiências reforça a conexão entre elas e a incapacidade, a negatividade, a inconveniência, a anormalidade e a inferioridade. (CONNOR; VALLE, 2014, p. 45).
}

Tais preconceitos dirigidos aos surdos, ainda fortemente vigentes em nossa sociedade, e compartilhados por uma maioria, são resultantes de uma construção

\footnotetext{
${ }^{2}$ Medicalização da surdez constitui-se em uma série de mecanismos pedagógicos corretivos, instaurados "nos princípios do século XX e vigentes até nossos dias [...] de práticas enceguecidas pela tentativa de correção, normalização e pela violência institucional." (SKLIAR, 2013, p. 7).
} 
social histórica estigmatizada, e edificada a partir de rígidas classificações e hierarquizações binárias do ser humano, que estabelecem que o normal é ser ouvinte, e que, portanto, a pessoa que não ouve é anormal. Desta forma, os pais, pela falta de informações, por negação e temerosos pelo futuro de seus filhos, acabam optando por privá-los do direito à Língua de Sinais e a uma educação bilíngue. Decidem pela normalização, apontada pela maioria médica como único caminho para mudar o fadado destino de uma criança surda, ao indicar apenas a oralização (treinamento da fala e da leitura labial) e o uso de tecnologias, como as próteses auditivas e, mais recentemente, o implante coclear ${ }^{3}$.

Problematizar a interface entre a família e o direito de acesso real ao ensino bilíngue, desvelando as intrínsecas relações referentes às possibilidades de usufruto do direito, previsto na legislação, que pressupõe o uso da Língua de Sinais como primeira língua para a criança surda, é o objetivo do presente texto. Para tal, parece ser imprescindível problematizar a essência das questões, umbilicalmente articuladas, entre identidade e diferença, revisitando os pilares que sustentam os binarismos em torno dos quais elas se organizam, trazendo, à luz, novas interpretações acerca destes.

\section{A LÍNGUA DE SINAIS E O DESENVOLVIMENTO DA CRIANÇA SURDA}

A criança que nasce surda fica impossibilitada de adquirir a linguagem oral de forma natural. Neste sentido, conforme destaca Marzolla (2012), a surdez afeta, de forma extremamente significativa, o processo de aquisição desta linguagem pela ausência de feedback auditivo. Desta forma, a oralização só pode ocorrer de maneira artificial, constituindo-se em uma trajetória longa e exaustiva de horas intermináveis de treinamento da fala e da leitura da palavra falada. $E$ apesar do intenso treinamento, a criança não consegue desenvolver uma "boa linguagem oral". (SOUZA, 1998, p. 9). A qualidade de produção da fala em geral, constitui-se insipiente diante do anseio de comunicação desta, prejudicando seu desenvolvimento global, o que pode ser vislumbrado pelo depoimento da doutora surda Karin Strobel (2008a, p. 14 -16) ao relatar sua experiência com a oralização:

\footnotetext{
${ }^{3}$ Implante coclear é um dispositivo eletrônico, colocado cirurgicamente na zona craniana posterior do pavilhão auricular, que tem como função transformar os sons e ruídos captados do ambiente em energia elétrica, desenvolvendo a sensação auditiva no implantado. (COELHO, MENDES, 2014).
}

(C) ETD-Educação Temática Digital Campinas, SP $\quad$ v.19 $\quad$ n.3 $\quad$ p. 882-900 jul./set. 2017 
[...] aprendi a falar, mas não sabia me comunicar adequadamente, só ficava repetindo as palavras, igual a um papagaio, sem entender seus significados, tudo mecânico e sem emoções. [...] Com a minha linguagem limitada eu não compreendia o que acontecia ao meu redor no dia a dia, mas eu era muito curiosa e queria saber o "porquê" de tudo e não recebia respostas, reprimia tudo dentro de mim e ficava muito agitada.

Nesta perspectiva, corrobora-se com Sacks (1998, p.10) que, ao descrever os prejuízos decorrentes da imposição da oralização, ressalta seu imenso pesar ao "[...] descobrir quantos surdos nunca adquirem as faculdades da linguagem ${ }^{4}-$ ou pensamento - e como uma vida medíocre pode lhes estar reservada".

A indignação, diante do aprisionamento de sujeitos surdos a esta condição de menos-valia, aumenta ao se destacar que ela deriva diretamente do não acesso a uma língua estruturada, apesar dos árduos processos de oralização a que são ou foram submetidos. Ao contrário, a aprendizagem da Língua de Sinais, por ser de modalidade visual, e não havendo comprometimento sensorial deste sentido, pode promover o acesso a uma língua plena, de forma natural, o que é capaz de suprir todas as necessidades comunicacionais e fomentar o mesmo desenvolvimento que ocorre com as crianças ouvintes, em decorrência de terem acesso a uma língua.

Reitera-se que a constituição da linguagem é fundamental para a relação humana, a partir da argumentação tecida por Vigotsky (2003) que enfatiza que é por meio dela que se estabelecem a relação dos sujeitos entre si e do indivíduo consigo mesmo e com a cultura. Sendo assim, é por intermédio da linguagem que ocorrem o processo de significação das relações e o acesso ao saber, aos valores e às normas de conduta, na medida em que

[...] a capacidade especificamente humana para a linguagem, habilita as crianças a providenciar instrumentos auxiliares na solução de tarefas difíceis, a superar a ação impulsiva, a planejar uma solução para um problema antes de sua execução e a controlar seu próprio comportamento. [...] As funções cognitivas e comunicativas da linguagem tornam-se, então, a base de uma forma nova e superior de atividade nas crianças, distinguindoas dos animais. (VIGOTSKY, 2003, p. 38).

Desta forma, é pela linguagem que as crianças constroem conhecimentos, estabelecem relações temporais e de identificação com o outro e consigo mesmas, transformando a realidade e sendo por ela transformadas. E é um divisor de águas, sensação relatada pelos próprios surdos, a passagem da ausência da linguagem para a

\footnotetext{
${ }^{4}$ No presente texto o termo linguagem é utilizado fazendo referência ao acesso pleno a uma língua estruturada, que é o foco de discussão do mesmo. O acesso a outras linguagens como a artística, cinematográfica, símbolos, gestos, entre outras, não são objetos de discussão neste.
}

(C) ETD-Educação Temática Digital Campinas, SP $\quad$ v.19 $\quad$ n.3 $\quad$ p.882-900 jul./set. 2017


aquisição natural da Língua de Sinais, já que o canal de percepção natural é visual. Conforme a surda Laborit (1994) descreveu, foi a partir do acesso à Língua de Sinais que pela

\footnotetext{
[...] primeira vez aprendia que podemos dar um nome às pessoas. Era formidável. Não sabia que havia nomes em minha família, a não ser o de papai e de mamãe. Encontrava-me com as pessoas, [...] mas elas não tinham nenhum nome para mim. Nenhuma definição. Estava muito surpresa em descobrir que um se chamava [...]. E acima de tudo que eu me chamava Emmanuelle. Compreendia, por fim, que tinha uma identidade. Eu: Emmanuelle. [...] Foi um renascimento, a vida começou mais uma vez. [...] A partir de então, somos seres humanos capazes de nos comunicar, capazes de nos construir. [...] Pouco a pouco, arrumei as coisas em minha cabeça e comecei a ter um pensamento, uma reflexão organizada, a comunicar-me [...]. (LABORIT, 1994, p. 51-52).
}

Nesta perspectiva, reenfatiza-se que somente pelo acesso a uma língua plena, no caso das crianças surdas, a Língua de Sinais, é que estas poderão se relacionar de forma dialógica, o que afeta diretamente o desenvolvimento do seu pensamento, da capacidade de abstração e da construção de sua individualidade. O relato de Laborit (1994) ilustra, claramente, a função da linguagem que, ao mesmo tempo em que é "um fator importante para o desenvolvimento mental da criança, exercendo uma função organizadora e planejadora de seu pensamento, tem também uma função social e comunicativa". (LACERDA, 2007 apud SALES; LACERDA, 2015, p. 18).

\section{DO BILINGUISMO A PARTIR DA INTERSEÇÃO ENTRE FAMÍLIA E ESCOLA}

Conforme referido, a maioria das crianças surdas nasce em famílias ouvintes, de modo que o ambiente linguístico na casa se efetiva pela língua oral. Porém, com o nascimento de um filho que não ouve, urge a necessidade da família de integrá-lo à comunidade surda, de modo que possa interagir com interlocutores usuários da Língua de Sinais o mais precocemente possível, a fim de que seu aprendizado se desenvolva de forma natural (LACERDA; LODI, 2009). Também os pais, desde o momento da descoberta da surdez, precisam buscar aprender a língua a fim de promover a comunicação fundamental dentro do ambiente familiar, para que seja possível o pleno desenvolvimento cognitivo-linguístico destas crianças, em equivalência ao das ouvintes em idade similar. (QUADROS, 1997 apud RIBEIRO, 2013).

Importante resgatar que a família é a primeira microestrutura social da criança e, por tal, de fundamental importância. E é neste espaço que se efetivarão as primeiras trocas físicas, afetivas e sociais da criança, devendo ser a família a mediadora original destas relações. (D’ANTINO, 1988). E esta mediação, necessariamente, perpassa as relações comunicacionais tecidas, que só ocorrerão de forma significativa se houver 
uma língua compartilhada entre a criança e sua família, nesse caso, a Língua de Sinais. Pondera-se, novamente, sobre a necessidade da família aprender, pois "se forem também videntes, podem aprendê-la sem encontrar nenhuma barreira sensorial que dificulte o processo de aprendizagem", enquanto que para a criança, pela surdez, conforme já referido, a aprendizagem da língua oral é extremamente complexa, lenta e nem sempre eficaz. (ANDREIS-WITKOSKI, 2015, p. 11).

Conforme este panorama é importante reenfatizar que, segundo Vigotsky, a linguagem determina o desenvolvimento do pensamento, e sua ausência o prejudica na medida em que "o crescimento intelectual da criança depende do domínio dos meios sociais, isto é, da linguagem". (VIGOTSKY, 1989, p. 44). Deste modo, como um efeito "dominó", pode-se afirmar que, em decorrência do atraso da linguagem, dá-se também uma demora na aprendizagem e, consequentemente, em seu processo evolutivo. E esta, que não teve, em seu ambiente familiar, acesso à Língua de Sinais, apresentará prejuízos no seu desenvolvimento linguístico, cognitivo, social e psicológico (LEITE; MCCLEARY, 2009), com reflexo no seu desempenho educacional.

Desta feita, vê-se que a questão do direito a um ensino bilíngue antecede a entrada desta criança em uma instituição de ensino, já que carrega uma série de entraves advindos da sua história familiar, não devendo ficar restrita à discussão sobre qual é a escola ideal dentro de uma perspectiva de ensino bilíngue: se uma escola bilíngue de surdos ou uma escola regular, em sistema inclusivo. Neste sentido, a ausência de ações políticas específicas, que estimulariam a real inclusão no seio familiar, que, obrigatoriamente, precisa estar alicerçado a interpelações bilíngues, repercute negativamente, pois, independente da escola a ser frequentada, a criança já chega ao espaço institucional com defasagem.

Vale observar que situação semelhante não ocorre quando o acesso à Língua de Sinais é promovido desde o nascimento, como ocorre com crianças que nascem surdas filhas de pais que também o são, comparadas com as que nascem em famílias ouvintes, segundo Skliar (2000, p. 141):

[...] apresentam melhores níveis acadêmicos, melhores habilidades para a aprendizagem da língua oral e escrita, níveis de leitura semelhantes aos do ouvinte, uma identidade equilibrada, e não apresentam os problemas sociais e afetivos próprios dos filhos surdos de pais ouvintes.

Outra questão importante a enfatizar é que, na maioria dos casos, as crianças surdas provenientes de famílias ouvintes, em função dos processos referidos anteriormente, chegam à escola praticamente sem nenhuma língua, ou seja, não dominam a língua oral o suficiente para compreender conhecimentos básicos e 
estabelecer relações comunicativas dentro da escola, e desconhecem a Língua de Sinais. Desta feita, mesmo quando os pais optam pelo ensino bilíngue em escola regular, com a presença de ILS, as crianças não se beneficiarão significativamente deste profissional, ao se desconsiderar a premissa apontada por Sá (2011, p. 58), de que:

[...] os intérpretes atuam quando há pessoas que já entendem a mensagem numa língua diferente da língua do emissor, quando há pessoas que já têm uma língua constituída, para a operação de seu processamento cognitivo.

Na situação em que as crianças ingressam numa escola inclusiva, com o direito ao ILS assegurado, mas ainda não sabem usar a Língua de Sinais, se prevê que a elas deva ser ofertado este aprendizado, preferencialmente por um instrutor surdo. Contudo, vale ressaltar que esta possibilidade é esporádica e as trocas ficam limitadas a poucos interlocutores, já que no contexto familiar é mantido apenas o uso da língua na modalidade oral, bem como com colegas e professores, ouvintes, o que perpetua a limitação ao acesso de informações e trocas formativas, de modo que, mesmo em idade adulta

\footnotetext{
muitos surdos, na verdade, não conhecem bem nenhuma língua: utilizam poucos sinais e, da língua oral, conhecem apenas palavras isoladas e frases simples - enfim, têm uma comunicação limitada. Esta limitação, advinda da falta de contato precoce com a Língua de Sinais, ou mesmo do contato restrito após adulto, faz com que até o trabalho com o intérprete na escola regular seja prejudicado, ou seja, não permite a necessária função de elo entre o professor e os conteúdos ministrados. (BRITO; SÁ, 2011, p. 211).
}

Para além da questão linguística, a família também é permanentemente solicitada a decidir sobre o direito de seus filhos de estudar em escola bilíngue, sem esquecer de que dentro de uma escola ouvinte, mesmo que o direito a ILS seja assegurado, a criança surda permanece isolada. Isto porque haverá poucos interlocutores falantes da Língua de Sinais, num espaço em que todo o ensino é perspectivado a partir da cultura ouvinte, que usa uma metodologia coerente com os processos de aprendizagem que têm ênfase na sonoridade (ANDREIS-WITKOSKI, 2012) e é um espaço institucional que, na prática, "continua sem saber trabalhar com as especificidades dos alunos surdos". (GUARINELLO, 2015, p. 12).

A importância da diferença entre ser surdo e ouvinte em geral não é perspectivada na escola regular e influencia significativamente o processo de ensino e aprendizagem. Isto porque a pessoa surda, diferentemente da ouvinte, orienta-se a partir de referências visuais, como exemplificado no relato de Witt, autora surda: 
Meus olhos são minha vida, são meu canal primordial, mais intenso, mais completo, mais arguto com a realidade, sendo que a percepção é maior, por exemplo, se alguém me pergunta como ocorreu um fato, explicarei o que vi, e não ouvi, se é feita esta mesma pergunta para o ouvinte, ele declarará pelo contrário: mais do que ouviu do que viu. (WITT, 2013, p. 55).

Inúmeros pesquisadores (ANDREIS-WITKOSKI, 2012; CAPOVILLA, 2011; SÁ, 2011 etc.), defendem que seja assegurado o ensino em ambiente naturalmente bilíngue, em que ocorram a interação, a identificação grupal e a autoidentificação. Também o desenvolvimento de relações de ensino e aprendizagem que respeitem as singularidades linguísticas e culturais alicerçadas na proposta bilíngue da Língua de Sinais como primeira língua e a Língua Portuguesa (no caso do Brasil), como segunda.

O direito ao ensino bilíngue é questão do contexto familiar, desde a identificação da surdez até as decisões tomadas pela família. Nesta perspectiva, reitera-se que mesmo que a opção da família seja por escola bilíngue, se não houver um ambiente linguístico compartilhado, permanecerá o hiato entre a criança e a família, pois não é responsabilidade da escola suprir processos formativos que deveriam ser construídos nas relações familiares, como ocorre com a criança ouvinte. No entanto, o que a realidade aponta é que se perpetua "certa indefinição de papéis da família e da escola quanto à responsabilidade de ambas no desenvolvimento do sujeito e aquisição da linguagem e, em muitos momentos, a escola parece assumir papéis marcadamente da família na educação da criança". (RODRIGUEIRO; YAEGASHI, 2013, p. 11).

\section{IDENTIDADE E DIFERENÇA: CONTESTANDO POSIÇÕES ESSENCIALISTAS}

É inegável que diante de pessoas com algum tipo de deficiência, as pessoas sentem um desconforto que evidencia o hiato em relação a elas, advindo do legado histórico no qual a todos era

[...] ensinado desde cedo a não apontar ou ficar olhando para alguém com deficiência, muito menos mencionar essa deficiência - como se essa pessoa fosse, de repente, perceber ou lembrar que tem deficiências e nos responsabilizar por termos feito isso. As boas maneiras exigem que olhemos para o lado e finjamos que não percebemos. [...] Fingir não notar os traços corporais de uma pessoa é desprezar o seu "modo de ser" como trágico demais para se reconhecer. (VALLE; CONNOR, 2014, p. 202).

E este silêncio é estabelecido de modo a não se questionar o processo normalizador pelo qual, ao sujeito definido como normal, se atribuem todas 
[...] as características positivas possíveis, em relação às quais as outras identidades só podem ser avaliadas de forma negativa. A identidade normal é "natural", desejável, única [...] A forma homogeneizadora da identidade normal é diretamente proporcional à sua invisibilidade (SILVA, 2014, p. 83).

Diante deste cenário, evidencia-se o como é complexo o nascimento de um filho com uma deficiência, na medida em que impõe uma nova realidade que destoa da expectativa de ter um filho "perfeito". No entanto, independente dos desafios que este nascimento acarreta no sentido de que a família precisará adaptar-se, providenciando cuidados que implicam gastos financeiros, de tempo e emocionais, e que a priori não estavam programados, permanecem as questões: - O que é perfeição? - O que é normalidade?

E especificamente em relação aos surdos, é importante considerar que a surdez, na sua perspectiva patológica, implica em denominá-los como imperfeitos, "anormais", definição essencialista, que segundo Woodward (2014, p. 15), pode ser "fundamentada tanto na história quanto na biologia". Neste sentido, importante ressaltar que, segundo o autor, a afirmação destas identidades é definida a partir de "verdades", sejam um "passado partilhado", sejam "verdades" biológicas.

Vê-se que a definição essencialista ajusta-se, perfeitamente, à perspectiva que se impõem aos surdos, com a naturalização de serem imperfeitos, já que, por esta lógica, tanto a "verdade" biológica torna-se inquestionável, na medida em que esta se edifica a partir da marca corporal da surdez, como o "passado partilhado", pelo qual, historicamente, estes sujeitos estão associados a situações de desprestígio social, mendicância, analfabetismo entre outras. Contudo, a artimanha utilizada para naturalizar esta visão essencialista faz-se a partir da incorporação das situações referidas, desconsiderando que estas não derivam diretamente da surdez, mas das históricas condições de existência que os aprisionaram e continuam limitando inúmeros surdos à condição de menos-valia.

Esta condição é decorrente de vários fatores como o preconceito social que Ihes é impingido, e que restringe os espaços e papéis possíveis de exercer. Também do abandono literal em instituições asilares, realidade que se perpetuou, e/ou a permanência apenas física, no contexto familiar, onde permanecem excluídos de qualquer troca significativa por não haver o compartilhamento de uma língua comum entre estes e a família. E, ainda, os catastróficos processos de ensino a que foram, e ainda são submetidos, que desconsideram as singularidades de ser surdo, características que exigem métodos diferenciados de mediação de ensino e aprendizagem que, sequer são consideradas, e automaticamente interpretadas como decorrências de um corpo danificado.

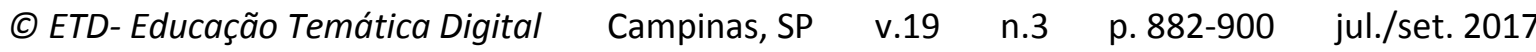


Reitera-se que dentro desta perspectiva, a surdez é lida através da naturalização de que ser surdo seja sinônimo de incapaz, de anormal. E a aceitação desta norma está enrijecida pela concepção de que se constitui também enquanto uma "verdade" biológica, quando apenas esta alicerçada a um processo de normalização que, como é característico deste, elege "arbitrariamente uma identidade específica como parâmetro em relação a qual as outras identidades são avaliadas e hierarquizadas". (SILVA, 2014, p. 83) . E a naturalização das tais "verdades" absolutas impede que as identidades surdas sejam percebidas. Ao se eleger a identidade ouvinte como norma, inviabiliza-se a possibilidade de vislumbrar as identidades surdas a partir da concepção de que:

[...] ser surdo é uma questão de vida. Não se trata de uma deficiência, mas de uma experiência na perspectiva de um mundo totalmente visual [...] Desta experiência visual surge a cultura surda apresentada pela Língua de Sinais, pelo modo diferente de ser, de se expressar, de conhecer o mundo, [...] (PERLIN; REIS, 2012, p. 39-40).

Interessante observar que a associação automática à anormalidade que, em geral, ocorre dentro de famílias ouvintes, e que influenciam as crianças a introjetar também o olhar que lhes é dirigido, no caso de crianças surdas filhas de pais surdos não tem a mesma conotação, pois para estas o ser surdo é a referência da normalidade. A seguir, transcreve-se o relato de uma relação de amizade entre duas crianças, o surdo americano Sam Supalla, que pertence a uma família com várias gerações de surdos, com uma ouvinte da mesma idade e ilustra a questão referida:

[...] Após alguns encontros tentativos, eles tornaram-se amigos. Ela era uma companheira satisfatória, porém havia o problema de sua "estranheza". Ele não conseguia falar com ela da maneira que conseguia falar com seus irmãos mais velhos e com seus pais. Ela parecia ter uma dificuldade extrema de compreender mesmo os gestos mais simples ou mais rudes [...] Um dia, Sam lembra-se vivamente, que ele finalmente entendeu porque a sua amiga era de fato estranha. Eles estavam brincando na casa dela quando, de repente, a mãe dela chegou até eles e animadamente começou a mexer sua própria boca. Como por mágica, a garota pegou uma casa de boneca e levou-a para outro local. Sam estava perplexo e foi para casa perguntar à sua mãe sobre exatamente que tipo de aflição a menina da porta ao lado tinha. Sua mãe explicou a ele que ela era ouvinte e por razão disto ela não sabia sinalizar; em vez disso, ela e a sua mãe falam, movimentam suas bocas para falarem entre si. Sam então perguntou se esta menina e a família dela era os únicos "daquele jeito". A mãe dele explicou que não; de fato, quase todas as pessoas eram como seus vizinhos. A sua própria família é que era incomum. [...]. (PADDEN; HUMPHRIES apud in STROBEL, 2008, p. 54).

\footnotetext{
${ }^{5}$ Ressalta-se que processo similar ocorre no estabelecimento de identidade sexual, que é fundamentada a partir do corpo, tal qual a maternidade se constitui em "outro exemplo na qual a identidade parece estar biologicamente fundamentada." (SILVA, 2014, p. 15).

(C) ETD-Educação Temática Digital $\quad$ Campinas, SP $\quad$ v.19 $\quad$ n.3 $\quad$ p.882-900 jul./set. 2017
} 
O exemplo relatado ilustra como o processo de normalização é uma construção social, mas que é mantido dentro da invisibilidade, o que reforça a identidade "normal" como "natural" e única possível. (SILVA, 2014). Ressalta-se que processo similar ocorre em relação à adoção das línguas de modalidade oral, como se fossem as únicas possíveis, desconsiderando a existência da modalidade visual, utilizada nas Línguas de Sinais, de modo que sobre estas é sonegado que

\footnotetext{
[...] a língua é uma instituição social da mesma espécie que todas as outras, é por acaso e por simples razões de comodidade que nos servimos do aparelho vocal como instrumento da língua; os homens poderiam também ter escolhido o gesto e empregar imagens visuais em lugar de imagens acústicas. (WHITNEY apud QUADROS; KARNOPP, 2004, p. 30).
}

Nesta perspectiva, reitera-se a necessidade de contestar os processos de normalização aos quais a família vai continuar submetendo o filho surdo, por acreditar que "para ser feliz, aceito e bem-sucedido, o surdo precisa ser como o ouvinte" (SÁ, 2002 , p. 329). No entanto, observa-se que além das reflexões tecidas até então, é importante refletir sobre o quanto, de acordo com Woodward (2014), as identidades são relacionais, de modo que a "existência dos deficientes, na verdade, é necessária para os normais se verem como normais". (BERGER, 2008, xxxix). A partir deste foco, faz-se imprescindível, não somente contestar a anormalidade, mas também adentrar um terreno sinuoso, no qual o intitulado "normal" sinta-se impelido a refletir sobre sua própria existência. E talvez aqui se localize um dos pilares que impõem maior resistência à desconstrução das visões essencialistas.

Neste sentido, relata-se que a tendência para desconstruir visões essencialistas, em geral, centra-se em buscar o reconhecimento do outro, o fora da norma, como também humano. Contudo, o processo de auto investigação, no qual o questionar a própria identificação como "normal", fica em segundo plano por conferir a este uma instabilidade que reverbera desde a célebre frase de William Shakespeare (entre 1599 e 1601): "Ser ou não ser: eis a questão."

Sobre o processo usual de buscar o reconhecimento do outro, resgata-se que um dos caminhos utilizados para questionar a soberania de uns sobre os outros, perpassa a teoria antipreconceito de Oz (2002). Segundo este autor, é necessário colocar-se no lugar do outro, para reconhecê-lo também como humano, desconstruindo o preconceito em relação a este. Esta troca de posições tende a gerar empatia em relação a este outro, pode influenciar uma melhor negociação de espaços e evidenciar a necessidade de promover a existência de direitos equitativos. E, na medida em que o "normal", experimente a dor da exclusão, mesmo que provisoriamente e de forma artificial, como se estivesse no lugar deste outro, não 
desejará passar por situação similar. Por tal, a priori, passará a aceitar que também aquele teria direitos que até então não questionava. Contudo, um viés deste processo, em seu interior, passa despercebido.

$\mathrm{O}$ ato de colocar-se no lugar do outro, por outro lado pode reforçar a visão de uma pessoa com deficiência somente pela experiência da deficiência. A pessoa que ouve, ao colocar-se no lugar da surda, pode vivenciar grande agonia por, repentinamente, imaginar-se sem a possibilidade de ouvir, sentimento que não condiz com o que sente aquele que nasceu surdo. Este se caracteriza como um ser visual e constrói sua relação com o mundo via este canal, "ouvindo" imagens, fenômeno cuja extensão um ouvinte não consegue captar, tal qual para quem nunca ouviu, os sons se constituem como fenômeno abstrato. Desta feita, corrobora-se com Connor e Valle (2014, p. 40) ao afirmarem que:

[...] as simulações, na verdade, trivializam as deficiências como algo que pode ser "experimentado" e "descartado". Enquanto esses exercícios vulgares ocorrem em muitas salas de aula, exercícios semelhantes, [...] na melhor das hipóteses, dariam aos alunos uma experiência de uma pessoa [...] fingir temporariamente [...] fingir ser. [...] Na pior das hipóteses, reforçaria estereótipos profundamente enraizados.

Diante das reflexões tecidas, parece fulcral, para além de contestar a anormalidade, conseguir se descentrar da norma, e questionar a sua própria normalidade; não entre binarismos, mas enquanto essência. Contudo, ao assumir a postura de se desligar de uma identidade que naturaliza privilégios como direitos inalienáveis, faz-se uma opção difícil, pelo fato de que os mesmos deixariam de thes ser assegurados automaticamente. Com isso, se formariam novos espaços de negociação entre estes, assim como os, até então, "normais" teriam dificuldade para legitimar a própria existência, já que não poderiam se utilizar da norma para construir sua identidade como soberana.

Neste sentido, reverbera o caráter relacional da identidade que se edifica a partir da diferença. Desta feita, ao se recusar que a identidade esteja fixada na rigidez da oposição binária, é preciso lidar com o que Hall (2014, p. 20) denomina como sendo a "fluidez da identidade, ao vê-la como uma questão de "tornar-se". . E ao contrário das identidades fixas, neste processo em que as certezas absolutas são recusadas e as identidades, fluidas, se impõe uma nova realidade na qual não há respostas prontas e definitivas para ser ou não ser. E isto implica na permanente busca por um ponto de equilíbrio não fixo, na tentativa de, talvez, alcançar o mesmo alvo referido pelo personagem Jean-Dominique, no filme "O escafandro e a borboleta", ao afirmar que: "sobrevivi me agarrando ao que me torna humano". 


\title{
PROBLEMATIZANDO AS RELAÇÕES PARENTAIS RUMO AO BILINGUISMO
}

Na perspectiva da desconstrução de posições essencialistas, vale destacar o discurso de Larrosa e Skliar (2001), num desdobramento da concepção de Hanna Arendt ${ }^{6}$ que escreveu sobre a condição humana da pluralidade, segundo os quais:

\begin{abstract}
A condição humana da pluralidade, poderíamos acrescentar, deriva do fato de que o que há são muitos homens, muitas histórias, muitos modos de racionalidade, muitas línguas e, seguramente, muitos mundos e muitas realidades. Isso é óbvio, embora nunca seja demais recordá-lo [...]. (LARROSA; SKLIAR, 2001, p. 17-18).
\end{abstract}

Diante do já discutido, se entende que se aos pais com filhos diagnosticados como surdos, forem promovidas as problematizações referidas, podem surgir possibilidades reais de assegurar, de fato, o direito ao bilinguismo. Isto porque a surdez passa a ser perspectivada como mais uma diferença a "ser reconhecida como apenas mais um aspecto das infinitas possibilidades da diversidade humana, pois ser surdo não é melhor ou pior do que ser ouvinte, é apenas diferente". (PIMENTA, 2011 apud HONORA, 2014, p. 24).

A partir desta nova abordagem, a expectativa é de que se possa evitar o olhar de "pena" em geral dirigido pelos pais às crianças surdas, movidos pela "tristeza, tendendo a se culpar e passando a se sentir pouco à vontade no brincar com um filho que não escuta", o que compromete o vínculo entre os mesmos. (ROSSI, 1994 apud FURTADO, 2008, p. 26). Com a ruptura deste "olhar", talvez seja possível mudar o perfil predominante das relações estabelecidas com os filhos surdos, marcadas, por exemplo, pela dificuldade de impor limites, situação similar à de pais de crianças com outras deficiências, pois parece plenamente aceitável, a justificativa de tolerar comportamentos inadequados, tal qual na situação abaixo:

[...] quando eu atendia uma mãe que deixava o filho abrir todas as balas que estavam na sua bolsa e, mal lambia uma, jogava fora e abria outra, eu perguntei: "Você deixaria o seu filho sem deficiência fazer isso" Ela me respondeu: "Nunca! É que este não entende." (SILVA, 2012, p. 69).

Ressalta-se a importância de romper com este olhar de vitimização que é dirigido à criança com deficiência, em geral, tal qual ao filho surdo, de forma que a família possa assumir o papel de mediação, oportunizando o seu desenvolvimento e crescimento saudáveis. Desta feita, as críticas dirigidas ao indivíduo surdo de que este "normalmente não conhece a polidez e o politicamente correto ou se expressa do jeito que pode e pensa, sem filtros que denotem o respeito ou o limite" (SILVA; NEMBRI,

${ }^{6}$ ARENDT, H. La condición humana. Paidós: Barcelona, 1993, p. 22. 
2012, p. 31), deixariam de ser usuais se, dentro do contexto familiar, houvesse a intervenção nas situações cotidianas que constroem, gradativamente, valores primordiais como o respeito ao outro.

No entanto, para haver o tipo de relação sugerida acima, volta-se à questão crucial: a necessidade de que no ambiente familiar seja instaurada uma língua plenamente compartilhada. Daí a importância da família aprender a Língua de Sinais, vencendo a sensação de "estranhamento aos olhos e mãos dos ouvintes" que esta aprendizagem confere, pois é uma língua "cujo canal de comunicação é totalmente alheio e diferente". (GESSER, 2012, p. 10).

Destaca-se também a relevância de ser assegurado, ao filho surdo, o direito à Língua de Sinais pelo contato com surdos sinalizantes, inclusive adultos, o que repercutirá em uma identificação positiva. Reitera-se a importância deste contato, na medida em que a família e o entorno social são predominantemente ouvintes, o que o induz a imaginar-se "único" e, consequentemente, deixando de perspectivar uma relação de futuro, o que levará a um drama existencial, similar ao relatado pela surda Laborit, que refere intenso sofrimento até o momento em que lhe foi oportunizado o contato com outro surdo adulto, conforme relatado pela mesma:

\footnotetext{
Não me via tornando-me grande. Via-me ficando sempre pequena. Por toda minha vida. Acreditava-me limitada ao estado presente. E, sobretudo, acreditava-me única, sem igual no mundo. [...] na minha cabeça as crianças surdas nunca cresciam. Iríamos morrer, assim, pequenos. [Quando conheceu Alfredo, um professor surdo adulto] compreendi imediatamente que não estava sozinha no mundo. Uma revelação imprevista. Um deslumbramento. [...] existia um futuro possível, já que Alfredo era adulto e surdo! Essa lógica cruel permanece enquanto as crianças surdas não se encontram com um adulto. Elas têm necessidade dessa identificação com os adultos [...]. (LABORIT, 1994, p. 32; 48).
}

Vale ressaltar que esta necessidade de identificação é tão grande que além do sofrimento, mantém permanente estado de observação que faz vasculhar, nos outros, características visuais similares às diferenças que percebe existir entre ela e as demais crianças, das quais desconhece a origem. Este processo é ilustrado no "mistério das bocas mexedeiras", narrado no livro de mesmo nome (OLIVEIRA, OLIVEIRA, CARVALHO, 2008), em que uma personagem infantil, ao desconhecer sua identidade surda, tenta desesperadamente entender como os outros, movimentando a boca, conseguem ter seus desejos atendidos, enquanto ela ao supostamente copiar o movimento articulatório, não tem satisfeitas as suas necessidades.

Ainda sobre este estado de interrogação que permanece, reitera-se o caráter fulcral de que à criança surda seja oportunizado viver em ambiente bilíngue no 
contexto familiar, de forma que suas relações sociais sejam promovidas, também, junto a outros surdos, ilustrando, com outro exemplo, o quanto a ausência destas possibilidades é problemática. Neste sentido, cita-se a história de uma menina surda, cuja família optou por oralização e protetização, sem que lhe fosse oportunizado entender sua própria diferença. $E$, ela, ingenuamente, quando criança tenta suprir sua necessidade de identificação de maneira absolutamente incongruente com sua existência, conforme relatado pela mesma:

\footnotetext{
Lembro-me de ver muita televisão quando pequena....Minha maior dificuldade era ouvir música, apesar de que eu acabava me identificando com os cantores, isso porque eu via muitos shows gravados na TV, e os cantores usavam fones e pontos de retorno, e eu achava que aqueles aparelhos deles eram os mesmos que eu usava, depois aprendi que não (risos). (LEITE; LEITE, p.77, 2014).
}

Sobre o episódio relatado, evidencia-se o estado de alienação e o quanto situações similares são prejudiciais a estas crianças surdas. Comparativamente ao ouvintes, estarão sempre em desvantagem se não lhes forem oportunizadas condições similares de informação e desenvolvimento. E tais possibilidades apontam para seu acesso à comunicação por meio da Língua de Sinais, desde a mais tenra infância no contexto familiar, estendendo o contato a outros espaços e interlocutores sinalizantes, inclusive outros surdos adultos.

Ressalta-se também, que o quanto antes for oportunizado a elas entender a própria diferença, a partir do caminho da desconstrução dos essencialismos trilhado pelos pais, mais preparadas estarão para enfrentar situações de preconceito e discriminação com que, invariavelmente, vão se deparar na sociedade. Contudo, entende-se que se também conseguirem problematizar a normatização, desnudando a incongruência da norma e dos binarismos impostos por este processo, poderão enfrentar tais situações sem se sentir humilhadas ou tendo que aceitar, passivamente, situações de exclusão. Poderão, ainda, vislumbrar as identidades surdas e ouvintes, sem posições essencialistas, mas a partir da perspectiva argumentada por Sandel (2007 apud BAUMAN; MURRAY, 2014, p. 89) de que "a diversidade humana nos ensina o valor de ir de uma ética dos indivíduos moldados, para contemplá-los em suas extraordinariamente ricas formas de ser".

\section{CONSIDERAÇÕES FINAIS}

O texto presente parte do pressuposto básico de que o direito ao ensino bilíngue para surdos perpassa, obrigatoriamente, a possibilidade de que a criança surda, desde a tenra infância, possa usufruir de um ambiente bilíngue no meio 
familiar, interagindo em Língua de Sinais com seus familiares e com outros interlocutores sinalizantes, inclusive surdos adultos.

No entanto, ciente de que esta opção raramente é trilhada pelas famílias que têm diagnosticada a surdez de seus filhos, e de todos os prejuízos decorrentes de se optar apenas pela oralização, aponta-se para a urgência de se estabelecer ações políticas efetivas e eficazes, específicas para dar apoio aos pais de crianças surdas. $\mathrm{E}$ sendo instituídas, devem ser informadas já no diagnóstico da surdez para conscientizálos da importância e das implicações do bilinguismo para seus filhos que, a priori, têm previsto o direito à Língua de Sinais como primeira língua e à língua oral, como segunda, o que não se restringe a uma escola, mas deve estar disponível a partir das relações estabelecidas em família.

Ao considerar que a resistência em relação à aceitação do filho surdo e de que este se torne usuário da Língua de Sinais está arraigada em concepções essencialistas que normatizam o ouvinte como normal, e o ser surdo, como anormal, sugere-se programas que possam questionar, junto aos familiares, estas posições fundadas no essencialismo, a fim de promover novas possibilidades de relações parentais, de modo que a primeira repercussão almejada seja a compreensão da necessidade de aprender a Língua de Sinais e possibilitar ao filho esta aprendizagem, construindo um ambiente bilíngue no contexto familiar.

Ressalta-se que no caminho sugerido, ao contrário do edificado a partir das identidades fixas, que carregam consigo a ilusória sensação de haver certezas absolutas, estas são recusadas vislumbrando o processo pelo qual as identidades são fluidas, onde não existem respostas prontas e definitivas, de modo que "educar um filho que nasceu surdo é um desafio tal qual educar um ouvinte, pois nenhum deles vem com manual". (ANDREIS-WITKOSKI, 2015, p. 81).

\section{REFERÊNCIAS}

BAUMAN, H-D. L.; MURRAY, J.J. Estudos surdos no século 21: "deaf-gain" e o futuro da diversidade humana. In: ANDREIS-WITKOSKI; S.; FILETAZ, M.R.P. (Orgs.) Educação de surdos em debate. Curitiba, PR: UTFPR, 2014, p. 67-92.

BERGER, J. Prefácio do editor: documentos sobre uma educação. In: KELLER, H. A história da minha vida: com suas cartas (1887-1901) e um relato suplementar sobre sua educação, incluindo trechos de narrativas e cartas da professora Anne Mansfield Sullivan, por John Albert Marcy. ed. rev. Rio de Janeiro, RJ: José Olympio, 2008, p. vixlv. 
BRASIL. Decreto no 5.626, de 22 de dezembro de 2005. Regulamenta a Lei no 10.436, de 24 de abril de 2002, que dispõe sobre a Língua Brasileira de Sinais - Libras e o art. 18 da Lei no 10.098, de 19 de dezembro de 2000. Diário Oficial da União. Brasília, 22 dez. 2005.

BRITO, J. L.; SÁ, N. R. L. de. Estudantes surdos na escola regular: questionando o paradigma da inclusão. In: SÁ, N. de. Surdos: qual escola? Manaus, AM: Valer e Edua, 2011, p. 195-204.

CAPOVILLA, F. C. Sobre a falácia de tratar as crianças ouvintes como se fossem surdas, e as surdas, como se fossem ouvintes ou deficientes auditivas: pelo reconhecimento do status linguístico especial da população escolar surda. In: SÁ, N. de. Surdos: qual escola? Manaus, AM: Valer e Edua, 2011, p. 77-100.

COELHO, O.: MENDES, M. Crianças surdas implantadas, trabalho pedagógico e envolvimento parental numa perspectiva de educação bilíngue. In: ANDREISWITKOSKI, S.; FILIETAZ, M.R.P. (Orgs.) Educação em debate. Curitiba, PR: UTFPR, 2014, p.129-146.

D' ANTINO, M.E.F. A máscara e o rosto da instituição especializada: marcas que o passado esconde e o presente abriga. São Paulo, SP: Mennon, 1988.

FURTADO, R. S. S. Surdez e a relação pais-filhos na primeira infância. Canoas, RS: ULBRA, 2008.

GESSER, A. O ouvinte e a surdez: sobre ensinar e aprender a Libras. São Paulo, SP: Parábola Editorial, 2012.

GUARINELLO, A. C. Prefácio. In: BAGAROLLO, M. F.; FRANÇA, D. M. V. R. (Orgs.).

Surdez, escola e sociedade: reflexões sobre fonoaudiologia e educação. Rio de Janeiro, RJ: Walk, 2015.

HALL, S. Quem precisa da identidade? IN: SILVA, T. T. da.; HALL, S.; WOODWARD, K. Identidade e diferença: a perspectiva dos estudos culturais (Org.) Petrópolis, RJ: Vozes, 2014, p 103-133.

HEATHERTON, T. F. et al. The social psychology of stigma. New York, London, The Guilford Press, 2000.

HONORA, M. Inclusão educacional de alunos com surdez: concepções e alfabetização. São Paulo, SP: Cortez, 2014.

LABORIT, E. O vôo da gaivota. São Paulo, SP: Best Seller, 1994.

LACERDA, C.B.F. de; LODI, A.C.B. A inclusão escolar de alunos surdos: princípios, breve histórico e perspectivas. In: LACERDA, C.B.F. de; LODI, A.C.B. (Orgs.) Uma escola, duas (C) ETD-Educação Temática Digital Campinas, SP $\quad$ v.19 $\quad$ n.3 $\quad$ p.882-900 jul./set. 2017 
línguas: letramento em língua portuguesa e língua de sinais nas etapas iniciais de escolarização. Porto Alegre, RS: Mediação, 2009.

LARROSA, J; SKLIAR, C. Habitantes de Babel. Belo Horizonte, MG: Autêntica, 2001.

LEITE,T; LEITE, T. Quem decide? Angra dos Reis, RJ: Costa Barros, 2014.

LEITE, T.de A.; MCCLEARY, L. Estudo em diário: fatores complicadores e facilitadores no processo de aprendizagem da Língua de Sinais Brasileira por um adulto ouvinte. IN; QUADROS, R. M. de; STUPF, M. R. (Orgs.) Estudos surdos IV. Petrópolis, RJ: Arara Azul, 2009, p. 242-277.

MARZOLLA, A. C. Atendimento psicanalítico do paciente com surdez. São Paulo, SP: Zagodoni, 2012.

OLIVEIRA, M. A. A. de; OLIVERIA, M. C. M. B. de; CARVALHO, O.V.G. de. Um mistério a resolver: o mundo das bocas mexedeiras. Belo Horizonte, MG: Del Rey, 2008.

OZ, A. Como curar um fanático? In: Contra o fanatismo. São Paulo, SP: Companhia das Letras, 2002 p. 13-41.

PERLIN, G.; REIS, F. Surdos: cultura e transformação contemporânea. In: PERLIN, G.; STUMPF, M. (Orgs.) Um olhar sobre nós surdos: leituras contemporâneas. Curitiba, PR: CRV, 2012, p. 29-46.

QUADROS, R. M. de; KARNOPP, L. B. Língua de sinais brasileira: estudos linguísticos. Porto Alegre, RS: Artmed, 2004.

RIBEIRO, V. P. Ensino de língua portuguesa para surdos: percepções de professores sobre adaptação curricular em escolas inclusivas. Curitiba, PR: Prismas, 2013.

RODRIGUERO, C. R. B.; YAEGASHI, S. F. R. A família e o filho surdo: uma investigação acerca do desenvolvimento psicológico da criança segundo a abordagem históricocultural. Curitiba, PR: CRV, 2013.

SÁ, N. R. L. Cultura, poder e educação de surdos. Manaus, AM: Edua, 2002.

SÁ, N. R. L. Escolas e classes de surdos: opção político-pedagógica legítima. In: SÁ, N. R. L.de. (Orgs.) Surdos: qual escola? Manaus, AM: Valer e Edua, 2011, p. 17-62.

SACKS, Oliver. Vendo vozes: uma viagem ao mundo dos surdos. Trad. Teixeira Motta. São Paulo, SP: Companhia das Letras, 1998.

SALES, A. de C. M.; LACERDA, C. B. F. de. Reflexões sobre o papel e a prática de intérpretes de língua de sinais no ensino fundamental. In: BAGAROLLO, M. F.; FANÇA, D. M. V. R. Surdez, escola e sociedade: reflexões sobre fonoaudiologia e educação. Rio de Janeiro, RJ: Walk, 2015, p. 17- 36.

$\begin{array}{llllll}\text { (C) ETD-Educação Temática Digital } & \text { Campinas, SP } & \text { v.19 } & \text { n.3 } & \text { p.882-900 } & \text { jul./set. } 2017\end{array}$ 
SCHNABEL J. O escafandro e a borboleta. Filme. Jean-Dominique Bauby (memórias); Ronald Harwood (roteiro adaptado). França, Estados Unidos, 2007. Drama. 112 min.

SILVA, A. N. de B. Heldy meu nome: rompendo barreiras da surdocegueira. São Paulo, SP: United Press, 2012.

SILVA, A. C. da; NEMBRI, A. G. Ouvindo o silêncio: surdez, linguagem e educação. 3. ed. Porto Alegre, RS: Mediação, 2012.

SILVA, T. T. da. A produção social da identidade da diferença. IN: SILVA, T. T. da; HALL, S.; WOODWARD, K. Identidade e diferença: a perspectiva dos estudos culturais (Org.). Petrópolis, RJ: Vozes, 2014, p 73-102.

SKLIAR, C. Abordagens socioantropológicas em educação especial. In: SKLIAR, C. (Org.) Educação \& exclusão: abordagens socioantropológicas em educação especial. Porto Alegre, RS: Mediação, 2000, p 7-21.

SKLIAR, C. Um olhar sobre o nosso olhar acerca da surdez e das diferenças. In: SKLIAR, C. (Org.). A surdez: um olhar sobre as diferenças. Porto Alegre, RS: Mediação, 6. ed. p. 7-32, 2013.

SOUZA, R. M. de. Línguas e sujeitos de fronteira: um pouco mais, e ainda, sobre a educação de surdos. In: SOUZA, R. M. de; SILVESTRE, N.; ARANTES, V. A. (Orgs.) Educação de surdos: pontos e contrapontos. São Paulo, SP: Summus, 2007, p, 17-48.

SOUZA, R. M. de. Que palavra que te falta? Linguística, educação e surdez. São Paulo, SP: Martins Fontes, 1998.

STROBEL, K. As imagens do outro sobre a cultura surda. Florianópolis, SC: UFSC, 2008.

STROBEL, K. Surdos: vestígios culturais não registrados na história. UFSC: Tese (Doutorado em Educação), 2008.

VALLE, J. W.; CONNOR, D. J. Ressignificando a deficiência: da abordagem social às práticas inclusivas na escola. Tradução: Fernando de Siqueira Rodrigues. Porto Alegre: AMGH, 2014.

VIGOTSKY, L. S. A formação social da mente: o desenvolvimento dos processos psicológicos superiores. Org. Michael Cole... [et al.]; Trad. José Cipolla Neto [et al.]. São Paulo, SP: Martins Fontes, 1994.

VIGOTSKY, L. S. Pensamento e linguagem. São Paulo, SP: Martins Fontes, 1989.

VILHALVA, S. Índios surdos: mapeamento das línguas de sinais do Mato Grosso do Sul. Petrópolis, RJ: Arara Azul, 2012.

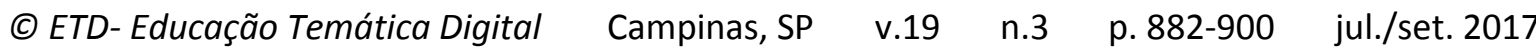


WITKOSKI, Sílvia Andreis. Educação de surdos pelos próprios surdos: uma questão de direitos. Curitiba, PR: CRV, 2012.

WITKOSKI, Sílvia Andreis. Introdução à Libras: língua, história e cultura. Curitiba, PR: UTFPR, 2015.

WITT, P. R. Surdez: silêncio em voo de borboleta. Porto Alegre, RJ: Movimento, 2013.

WOODWARD, K. Identidade e diferença: uma introdução teórica e conceitual. In: SILVA, T. T. da; HALL, S.; WOODWARD, K. Identidade e diferença: a perspectiva dos estudos culturais (Org.). Petrópolis, RJ: Vozes, 2014, p.7-72. 